\title{
Meningkatkan proses dan hasil belajar siswa pada tema selamatkan makhluk hidup dengan metode ekplorasi lingkungan sekitar pada siswa kelas VI
}

\author{
Desrina \\ SDN 23 Painan Utara Kecamatan IV Jurai Pesisir Selatan
}

\begin{abstract}
The background of this research is that science learning has been theoretical without students knowing how the application of learning in everyday life and learning Science does not encourage students to care about the environment so students cannot know the process of a natural event in living things, such as plants. the author wants students to be closer to nature and at the same time can increase the process and learning outcomes, especially those related to science. The approach used is a qualitative approach. The research data was obtained from the results of the assessment of learning implementation plan (RPP), the results of the observation sheet on the implementation of learning with the Approach to Environmental Exploration Approach from the aspects of teachers, students and evaluation. The data source is the process of implementing the Neighborhood Exploration approach to the theme of Saving Sentient Beings in class VI of SD Negeri 23 Painan Utara. The results of the study are the learning of Science with the Approach to the Environmental Environment Exploration will lead to an attitude of student concern for the environment, motivating students to learn. This is evidenced by the increase in student learning outcomes, namely cycle I completeness of students $61 \%$ with an average value of 73 and cycle II completeness of students $83 \%$ with an average value of 84 . Based on the results of the study, it is suggested to the following parties (1) for teachers The Neighborhood Exploration approach in learning Science because it can cause students to care about the environment and improve student learning outcomes, (2) the reader should be able to add knowledge to the reader.
\end{abstract}

Keywords: hasil belajar, selamatkan makhluk hidup, eksplorasi lingkungan

This is an open access article distributed under the Creative Commons Attribution License, which permits unrestricted use,
distribution, and reproduction in any medium, provided the original work is properly cited. (C2019 by author

\section{PENDAHULUAN}

Kurikulum 2013 adalah langkah besar Indonesia untuk memperbaiki kualitas pendidikan di Indonesia. Salah satu landasan empiris diterbitkannya kurikulum 2013 adalah hasil dari PISA yang menunjukkan peringkat Indonesia masih menduduki peringkat 5 besar terbawah dari 65 negara. Hasil studi TIMSS (Trends in International Mathematics and Science Study) menunjukkan siswa Indonesia berada di ranking yang rendah dalam kemampuan (1) memahami informasi yang kompleks, (2) teori, analisis dan pemecahan masalah, (3) pemakaian alat, prosedur dan pemecahan masalah, dan (4) melakukan investigasi. Hasil studi ini menunjukkan perlu ada perubahan orientasi kurikulum dengan tidak membebani siswa dengan konten namun lebih berorientasi pada aspek kemampuan essensial yang diperlukan semua warga untuk berperan serta dalam membangun negara pada masa mendatang (Cahyani, Rustaman, Arifin, \& Hendriani, 2014) . Prinsip tersebut sesuai dengan prinsip literasi sains bahwa konten yang diterima siswa harus sesuai dengan kehidupannya di masa kini dan mendatang. 
Seiring dengan perkembangan ilmu pengetahuan dan teknologi yang semakin canggih saat ini, maka diperlukan berbagai kegiatan yang dapat dilakukan untuk memahami gejala alam agar memiliki kebermaknaan bagi anak didik. Tidak dapat dipungkiri bahwa kegiatan Sains belum sepenuhnya dapat dilakukan dan belum sepenuhnya memperoleh dukungan baik dari orang tua maupun pendidik(Sulistyanto \& Wiyono, 2008).

Dalam pembelajaran sains yang diterapkan di sekolah selama ini, siswa beranggapan bahwa sains merupakan pelajaran yang terpisah dari tempat mereka berada. Hal ini menyebabkan siswa tidak mampu mengaitkan dan menggunakan konsep-konsep sains yang dipelajari untuk menyikapi permasalahan dalam kehidupan mereka (Holbrook, et al., 2005).

Proses mempelajari Sains dengan benar akan melatih kita menggunakan prinsip-prinsip logika dalam mengevaluasi apakah informasi yang kita peroleh itu benar atau salah. Proses pelatihan ini akan mengasah ketajaman kita dalam berpikir kritis dan menggunakan logika.

Guru membelajarkan Sains cenderung bersifat hafalan tanpa mereka tahu bagaimana pengaplikasian pembelajaran dalam kehidupan sehari- hari. Hal ini perkuat oleh (Iskandar, Sukasno, \& Charli) "Dalam proses pembelajaran, anak kurang didorong mengembangkan kemampuan berfikir dan proses pembelajaran dikelas diarahkan kepada kemampuan anak untuk menghafal informasi, tanpa dituntut untuk memahami informasi yang diingatnya itu untuk menghubungkan dengan kehidupan sehari- hari akibatnya siswa pintar secara teoritis, tetapi mereka miskin aplikasi”(Fadhilaturrahmi, 2017).

Pelajaran Sains dapat memberikan pengaruh terhadap perkembangan sosio-emosional, fisik, kreativitas dan perkembangan kognitif. Tahapan di setiap usia kronologis dan perkembangan sangat menentukan jenis dan tingkat kesulitan dalam permainan Sains . Itu berarti permainan Sains haruslah diberikan dari hal-hal yang sederhana menuju ke tingkatan yang lebih kompleks. Pada dasarnya kegiatan-kegiatan dalam konsep Sains dapat dipelajari melalui pengalaman sehari-hari yang nyata dan sederhana. Suasana yang menarik dan menyenangkan akan memotivasi anak untuk terus menerus mancari jawaban terhadap apa yang ia pikirkan dan ingin ia buktikan

Di SD Negeri 23 Painan Utara Kecamatan IV Jurai pengetahuan Sains anak mengenai lingkungan sekitarnya kurang berkembang. Hal ini disebabkan karena kurangnya pengalaman anak dalam hal pengetahuannya mengenai lingkungan secara nyata. Juga karena kurangnya keinginan anak untuk mencoba dan memecahkan masalah mengenai Sains. Pengetahuan Sains anak yang kurang memuaskan juga dikarenakan guru dalam kegiatan pembelajaran banyak yang dilakukan di dalam kelas. Selain itu juga guru dalam penyampaian materi bersifat teori atau cenderung ceramah dan tidak menggunakan benda kongkrit sebagai medianya. Hal ini membuat guru resah, apalagi hasil belajar yang kurang memuaskan terutama dalam pengungkapan konsep Sains anak. Melihat kondisi yang ada maka penulis merencanakan melakukan Penelitian Tindakan Kelas dengan judul “ Meningkatkan Proses dan Hasil Belajar Siswa pada Tema Selamatkan Makhluk Hidup dengan Metode Eksplorasi Lingkungan Sekitar pada Siswa Kelas VI SD Negeri 23 Painan Utara Kecamatan IV Jurai Kabupaten Pesisir Selatan”. Dengan mengembangkan pengetahuan Sains melalui pendekatan eksplorasi lingkungan sekitar diharapkan anak dapat mempunyai pengetahuan dan pengalaman yang mengasyikkan dan berguna bagi kehidupannya.

\section{METODE}

Pendekatan yang peneliti gunakan adalah pendekatan kualitatif, karena sesuai dengan penelitian tindakan kelas, peneliti ingin mengamati fenomena yang terjadi di dalam kelas. Jenis penelitian ini adalah Penelitian Tindakan Kelas (PTK) atau Action Research. Menurut Ritawati (2008:11)" PTK adalah Kegiatan penelitian yang dilakukan dalam kelas untuk mencermati suatu objek dengan menggunakan cara atau metodologi tertentu untuk memperoleh data atau memperoleh informasi yang bermanfaat dalam meningkatkan kualitas guru dalam melaksanakan pembelajaran”.

Hakikat PTK terletak adanya tindakan dalam situasi yang alami untuk memecahkan permasalahan dalam pembelajaran Sains di SDN 23 Painan Utara . Proses PTK merupakan siklus yang ditandai dari aspek pengembangan, perencanaan, melakukan tindakan, dan melakukan refleksi yaitu perenungan terhadap perencanaan, kegiatan tindakan dan kesuksesan hasil yang diperoleh. Sesuai dengan prinsip umum PTK setiap tahapan dan siklusnya selalu secara partisipatoris dan kolaborasi antara peneliti, guru, kepala sekolah dalam 
sistem persekolahan. Hal ini sesuai dengan pernyataan (Mahyuddin \& Ariani, 2008)"Proses PTK merupakan proses daur ulang atau siklus yang ditandai dari aspek pengembangan, perencanaan, melakukan tindakan, dan melakukan refleksi “.

Proses penelitian tindakan kelas merupakan proses daur ulang sampai peningkatan yang diharapkan berhasil. (Arikunto \& Suhardjono, 2006) menjelaskan bahwa: "Proses penelitian tindakan kelas merupakan proses daur ulang yang diawali dengan perencanaan tindakan, penerapan tindakan, mengobservasi dan mengevaluasi proses dan hasil tindakan, dan melakukan refleksi, dan seterusnya sampai perbaikan atau peningkatan yang diharapkan dapat tercapai"

Sumber data penelitian adalah proses pembelajaran tema Selamatkan Makhluk Hidup di kelas VI SDN 23 Painan Utara, yang meliputi perencanaan pembelajaran, pelaksanaan pembelajaran, kegiatan evaluasi pembelajaran, prilaku guru dan siswa selama proses pembelajaran. Data diperoleh dari subjek yang diteliti dan siswa kelas VI SDN 23 Painan Utara dengan jumlah 28 orang.

Teknik pengumpulan data penelitian dilaksanakan dengan menggunakan lembaran penilaian RPP, lembaran pengamatan pelaksanaan pembelajaran dengan pendekatan Eksplorasi Lingkungan Sekitar dari aspek guru dan aspek siswa, dan evaluasi. Untuk masing- masingnya diuraikan sebagai berikut :

Data yang diperoleh dalam penelitian dianalisis dengan menggunakan Model Analisis Data Kualitatif yakni analisis data dimulai dengan menelaah sejak pengumpulan data sampai seluruh data terkumpul. Data tersebut direduksi berdasarkan masalah yang diteliti, diikuti penyajian data dan terakhir penyimpulan. Tahap analisis yang demikian dilakukan berulang-ulang begitu data selesai dikumpulkan pada setiap tahap pengumpulan data dalam setiap tindakan.

Analisis data dilakukan terhadap data yang telah direduksi baik data perencanaan, pelaksanaan, maupun data evaluasi. Analisis data dilakukan dengan cara terpisah-pisah. Hal ini dimaksudkan agar dapat ditemukan berbagai informasi yang spesifik dan terfokus pada berbagai informasi yang mendukung pembelajaran dan yang menghambat pembelajaran. Dengan demikian pengembangan dan perbaikan atas berbagai kekurangan dapat dilakukan tepat pada aspek yang bersangkutan. Diharapkan berhasil, jika belum maka siklus diteruskan sampai berhasil.

\section{HASIL}

Penelitian ini dilaksanakan pada kelas VI SD Negeri 23 Painan Utara Kecamatan IV Jurai Kabupaten Pesisir Selatan tema Selamatkan Makhluk Hidup dan fokus penelitian pada Sains semester I tahun ajaran 2018/2019. Dalam pelaksanaan tindakan dibagi 2 siklus dengan rentang waktu 1 minggu peneliti berkolaborasi dengan teman sejawat sebagai pengamat atau obsever.

Dalam pelaksanaan tindakan pembelajaran, peneliti bertindak sebagai guru, sedangkan teman sejawat sebagai pengamat.Tahap-tahap pembelajaran setiap tindakan disesuaikan dengan tahap pembelajaran. Adapun perincian setiap siklus adalah sebagai berikut:

\section{Hasil Penelitian Siklus I}

1. Perencanaan

Pendekatan Ekplorasi Lingkungan Sekitar yang digunakan dalam tema Selamatkan Makhluk Hidup disusun dan diwujudkan dalam bentuk Rencana Pelaksanaan Pembelajaran (RPP). RPP disusun berdasarkan analisis kurikulum Tingkat satuan Pendidikan (KTSP) kelas VI semester I RPP disajikan dalam 2 x pertemuan yaitu $4 \times 35$ menit.

2. Pelaksanaan

Pertemuan I

Guru memberikan salam dan mengajak semua siswa berdo'a menurut agama dan keyakinan masing-masing. Guru mengecek kesiapan diri dengan mengisi lembar kehadiran dan memeriksa kerapihan pakaian, posisi dan tempat duduk disesuaikan dengan kegiatan pembelajaran. Menginformasikan tema yang akan dibelajarkan yaitu tentang "Tumbuhan Sumber Kehidupan”.Guru menyampaikan tahapan kegiatan yang meliputi kegiatan mengamati, menanya, mengeksplorasi, mengomunikasikan dan menyimpulkan. 


\section{Pertemuan 2}

Pertemuan kedua dilaksanakan dengan langkah-langkah pembelajaran sebagai berikut : Guru memberikan salam dan mengajak semua siswa berdo'a menurut agama dan keyakinan masing-masing. Guru mengecek kesiapan diri dengan mengisi lembar kehadiran dan memeriksa kerapihan pakaian, posisi dan tempat duduk disesuaikan dengan kegiatan pembelajaran. Menginformasikan tema yang akan dibelajarkan yaitu tentang " Tumbuhan Sumber Kehidupan". Guru menyampaikan tahapan kegiatan yang meliputi kegiatan mengamati, menanya, mengeksplorasi, mengomunikasikan dan menyimpulkan. Adapun langkah-langkah kegiatan inti antara lain : 1) Siswa mengamati gambar bagian-bagian alat reproduksi bunga dan membaca proses perkembangbiakan generatif. (Mengamati); 2) Siswa mengamati proses perkembangbiakan generatif dan manfaat dari perkembangbiakan generatif; 3) Siswa mengamati bagian-bagian bunga sempurna berikut; 4) Kegiatan eksplorasi Lingkungan yaitu Siswa mencari bunga di lingkungan sekolah dan mengamati bagian - bagiannya; 5) Siswa mencari informasi dari berbagai sumber mengenai proses perkembangbiakan generatif tumbuhan. (Mengekplorasi); 5) Siswa mencari informasi dari berbagai sumber mengenai jenis penyerbukan. (Mengekplorasi); 6) Siswa mengamati lingkungan di sekitarnya untuk menemukan satu jenis tanaman dan cara penyerbukannya. Kemudian siswa menuliskan hasilnya pada kolom yang tersedia. (Mengamati); 7) Siswa mendiskusikan hasilnya dengan kelompoknya; 8) Guru memastikan semua siswa mengerjakan dengan teliti dan mandiri. Guru dapat melakukan penilaian sikap saat siswa mengerjakan latihan dengan kriteria yang ditentukan, seperti teliti, percaya diri, dan mandiri

\section{Hasil Pengamatan dan Penilaian Siklus I}

Hasil pengamatan yang dilakukan oleh teman sejawat sebagai observer terhadap keaktifan/partisipasi, kerjasama/kerja kelompok, dan kedisiplinan dari 28 orang siswa menunjukkan hal sebagai berikut :

\begin{tabular}{|c|c|c|c|c|c|c|c|}
\hline \multirow[t]{2}{*}{$\overline{\text { No }}$} & \multirow[t]{2}{*}{ Aspek yang Dinilai } & \multicolumn{2}{|c|}{ Sangat Baik } & \multicolumn{2}{|c|}{ Baik } & \multicolumn{2}{|c|}{ Cukup } \\
\hline & & $\mathrm{Jml}$ & $\%$ & $\mathrm{Jml}$ & $\%$ & $\mathrm{Jml}$ & $\%$ \\
\hline 1 & Keaktifan/Partispasi & 5 & $18 \%$ & 7 & $25 \%$ & 16 & $36 \%$ \\
\hline 2 & Kerjasama/Kerja Kelompok & 8 & $29 \%$ & 7 & $25 \%$ & 13 & $29 \%$ \\
\hline 3 & Kedisiplinan & 6 & $21 \%$ & 8 & $29 \%$ & 14 & $36 \%$ \\
\hline & Rata-Rata $\%$ & & $23 \%$ & & $26 \%$ & & $29 \%$ \\
\hline
\end{tabular}

Selain itu, penulis sendiri juga melakukan analisis terhadap hasil penilaian pengetahuan secara tertulis dalam siklus I dan diperoleh hasil sebagai berikut :

\begin{tabular}{|c|c|c|c|c|c|c|c|}
\hline \multirow[t]{2}{*}{ No } & \multirow[t]{2}{*}{ Aspek yang Dinilai } & \multicolumn{2}{|c|}{$\begin{array}{c}\text { Sangat Baik } \\
86-100\end{array}$} & \multicolumn{2}{|c|}{$\begin{array}{c}\text { Baik } \\
71-85\end{array}$} & \multicolumn{2}{|c|}{$\begin{array}{c}\text { Cukup } \\
>70\end{array}$} \\
\hline & & $\overline{\mathrm{jml}}$ & $\%$ & $\overline{\mathrm{jml}}$ & $\%$ & $\overline{\mathrm{jml}}$ & $\%$ \\
\hline $\mathbf{1}$ & Hasil Penilaian Pengetahuan & 6 & $21 \%$ & 9 & $32 \%$ & 13 & $47 \%$ \\
\hline
\end{tabular}

3. Refleksi Siklus I

Refleksi dilakukan secara koloboratif antara penulis dan teman sejawat sebagai observer yang telah melakukan pengamatan pada saat pembelajaran dengan tema Selamatkan Makhluk Hidup focus pembelajaran Sains. Dari hasil diskusi dengan teman sejawat sebagai observer dapat ditemukan hal-hal sebagai berikut :

a. Langkah-langkah pembelajaran telah berjalan sesuai dengan yang telah direncanakan dalam RPP.

b. Penguasaan guru terhadap materi pembelajaran sudah baik. 
c. Motivasi dan perhatian guru terhadap siswa masih kurang, dan perlu lebih ditingkatkan.

d. Partisipasi siswa secara personal masih kurang,

e. Kerjasama dalam kelompok kurang kompak atau hanya sebagian kecil yang betul-betul bekerja dalam kelompok.

\section{Siklus II}

1. Perencanaan

Dalam siklus ke II ini, penulis melanjutkan materi pembelajaran dengan tema masih Selamatkan Makhluk Hidup dan penelitian yang penulis lakukan tetap Pendekatan Ekplorasi Lingkungan Sekitar dan diwujudkan dalam bentuk Rencana Pelaksanaan Pembelajaran (RPP). RPP disusun berdasarkan analisis kurikulum Tingkat satuan Pendidikan (KTSP) kelas VI semester I RPP disajikan dalam 2 x pertemuan yaitu 4 x 35 menit.

\section{Pelaksanan}

a. Pertemuan 1

Guru memberikan salam dan mengajak semua siswa berdo'a menurut agama dan keyakinan masing-masing.Guru mengecek kesiapan diri dengan mengisi lembar kehadiran dan memeriksa kerapihan pakaian, posisi dan tempat duduk disesuaikan dengan kegiatan pembelajaran.Menginformasikan tema yang akan dibelajarkan yaitu tentang "Tumbuhan Sumber Kehidupan".Guru menyampaikan tahapan kegiatan yang meliputi kegiatan mengamati, menanya, mengeksplorasi, mengomunikasikan dan menyimpulkan. Adapun langkah-langkah pembelajarannya sebagai berikut :

1) Siswa diingatkan kembali tentang perkembang-biakan tumbuhan secara generatif yaitu perkem-bangbiakan melalui perkawinan. Ingatkan kepada siswa tentang kebesaran ciptaan Tuhan Yang Maha Esa mampu membuat serangga bekerja-sama dengan bunga untuk melestarikan tumbuhan di Bumi ini. (Mengkomunikasikan)

2) Siswa diajak keluar pekarangan sekolah dalam kegiatan Ekplorasi Lingkungan Sekolah secara berkelompok.

3) Siswa ditugaskan untuk mencari contoh tanaman dalam lingkungan sekolah yang berkembang biak dengan vegetative alami

4) Siswa diminta mengamati daun cocor bebek yang berkembang biak secara vegetatif alami, yaitu dengan tunas pada daun. (Mengamati)

5) Siswa diminta membuat minimal dua pertanyaan mengenai tanaman cocor bebek. (Menanya)

6) Siswa melakukan diskusi kelas tentang perkembang biakan vegetatif alami beserta contohnya.

7) Menyimpulkan pelajaran dan memberi motivasi dan tugas tentang Jenis perkembangbiakan yang lainnya

\section{b. Pertemuan ke 2}

1) Adapun langkah-langkah pembelajaran pada pertemuan kedua ini sebagai berikut : Siswa mengamati gambar proses penyerbukan secara generatif.

2) Bertanya jawab tentang proses penyerbukan

3) Siswa mengklasifikasikan beragam tumbuhan yang ada di sekitar sekolah menjadi dua jenis berdasarkan cara perkembangbiakannya, yaitu vegetatif dan generatif dalam bentuk diagram venn. (Mengekplorasi)

4) Untuk memastikan klasifikasi mereka benar, maka motivasikan siswa untuk mencari informasi tentang kedua jenis perkembangbiakan tersebut.

5) Siswa menganalisis dan menyimpulkan hubungan antara perkembangbiakan tumbuhan dengan kelangsungan makhluk hidup lainnya.

\section{Hasil Pengamatan dan Penilaian Siklus II}

Hasil pengamatan yang dilakukan oleh teman sejawat sebagai observer terhadap keaktifan/partisipasi, kerjasama/kerja kelompok, dan kedisiplinan dari 28 orang siswa pada siklus ke II menunjukkan hal sebagai berikut : 


\begin{tabular}{|c|c|c|c|c|c|c|c|}
\hline \multirow[t]{2}{*}{ No } & \multirow[t]{2}{*}{ Aspek yang Dinilai } & \multicolumn{2}{|c|}{ Sangat Baik } & \multicolumn{2}{|c|}{ Baik } & \multicolumn{2}{|c|}{ Cukup } \\
\hline & & $\mathbf{J m l}$ & $\%$ & $\mathbf{J m l}$ & $\%$ & $\mathbf{J m l}$ & $\%$ \\
\hline 1 & Keaktifan/Partispasi & 13 & $46 \%$ & 12 & $43 \%$ & 3 & $11 \%$ \\
\hline 2 & Kerjasama/Kerja Kelompok & 10 & $36 \%$ & 14 & $50 \%$ & 4 & $14 \%$ \\
\hline 3 & Kedisiplinan & 10 & $36 \%$ & 15 & $53 \%$ & 3 & $11 \%$ \\
\hline & Rata-Rata \% & & $39 \%$ & & $49 \%$ & & $12 \%$ \\
\hline
\end{tabular}

Pada siklus II penulis tetap melakukan analisis terhadap hasil penilaian pengetahuan secara tertulis dalam siklus II dan diperoleh hasil sebagai berikut :

\begin{tabular}{|c|c|c|c|c|c|c|c|}
\hline \multirow[t]{2}{*}{ No } & \multirow[t]{2}{*}{ Aspek yang Dinilai } & \multicolumn{2}{|c|}{$\begin{array}{c}\text { Sangat Baik } \\
86-100\end{array}$} & \multicolumn{2}{|c|}{$\begin{array}{c}\text { Baik } \\
71-85\end{array}$} & \multicolumn{2}{|c|}{$\begin{array}{r}\text { Cukup }_{>70} \\
\end{array}$} \\
\hline & & $\mathbf{J m l}$ & $\%$ & $\mathbf{J m l}$ & $\%$ & Jml & $\%$ \\
\hline $\mathbf{1}$ & Hasil Penilaian Pengetahuan & 11 & $39 \%$ & 14 & $50 \%$ & 3 & $11 \%$ \\
\hline
\end{tabular}

\section{Refleksi Siklus II}

Refleksi dilakukan secara koloboratif antara penulis dan teman sejawat sebagai observer yang telah melakukan pengamatan pada saat pembelajaran dengan tema Selamatkan Makhluk Hidup focus pembelajaran Sains. Dari hasil diskusi dengan teman sejawat sebagai observer dapat ditemukan hal-hal sebagai berikut :

a. Langkah-langkah pembelajaran telah berjalan sesuai dengan yang telah direncanakan dalam RPP.

b. Penguasaan guru terhadap materi pembelajaran sudah baik.

c. Motivasi dan perhatian guru terhadap siswa sudah baik.

d. Partisipasi siswa secara klasikal sudah sangat baik.

e. Kerjasama dalam kelompok sudah sangat baik.

Dari hasil diskusi atau refleksi ini dapat ditarik kesimpulan penelitian ini cuku sampai siklus II .

\section{PEMBAHASAN}

Dari hasil pengamatan observer inilah penulis dapat gambaran aktifitas siswa dari beberapa aspek yang telah penulis sepakati dengan observer yaitu keaktifan atau partisipasi, kerjasama/kerja kelompok dan kedisiplinan. Dengan hasil sebagai berikut :

1. Keaktifan / Partisipasi

Dari hasil pengamatan dapat diuraikan keaktifan siswa selama dalam penelitian ini adalah meningkat dari siklus I ke siklus II. Pada siklus I berdasarkan hasil pengamatan terdapat 5 orang atau $18 \%$ siswa bernilai sangat baik pada siklus II meningkat menjadi 13 orang atau 46\%, bernilai baik 7 orang atau $25 \%$ meningkat menjadi 12 orang atau $43 \%$ dan bernilai cukup 16 orang atau $36 \%$ pada siklus I berkurang menjadi 3 orang atau $11 \%$ pada siklus II.

2. Kerjasama/Kerja Kelompok

Dari aspek Kerjasama/kerja kelompok dapat digambar sebagai berikut : pada siklus I menunjukkan Kerejasama sangat baik hanya 8 orang (29\%) pada siklus II meningkat menjadi 10 orang (36\%), bernilai baik dari 7 orang $(25 \%)$ pada siklus I meningkat menjadi 14 orang $(50 \%)$ pada siklus II dan memperoleh nilai cukup 13 orang $(46 \%)$ berkurang menjadi 4 orang (14\%) pada siklus II.

3. Kedisiplinan

Sementara itu dari aspek kedisiplinan siswa dalam mengikuti kegiatan pembelajaran dapat disampaikan hasil pengamatan sebagai berikut : pada siklus I yang memperoleh kedisiplinan sangat baik 6 orang (21\%) pada siklus II meningkat menjadi 10 orang ( $36 \%$ ), yang memperoleh kedisiplinan baik pada siklus I ada 8 
orang $(29 \%)$ pada siklus II meningkat menjadi 15 orang (53\%) dan yang memperoleh tingkat kedisiplinan cukup pada siklus I sebanyak 14 orang menurun pada siklus II menjadi 3 orang (11\%)

Disamping ketiga aspek diatas, berdasarkan hasil analisis ulangan/penilaian pengetahuan dapat pula penulis uraikan sebagai berikut : bernilai sangat baik (rentang 86-100) pada siklus I berjumlah 6 orang, pada siklus II meningkat menjadi 11 orang, bernilai baik (76-85) pada siklus I 9 orang meningkat pada siklus II sebanyak 14 orang dan yang memperoleh nilai cukup (>70) pada siklus I sebanyak 13 orang pada siklus II tinggal 3 orang.

Dari paparan diatas dapat disimpulkan bahwa pendakatan Ekplorasi Liangkungan Sekitar dapat meningkatkan hasil dan proses pembelajaran Sains tema Selamatkan Makhluk Hidup pada siswa kelas VI SD Negeri 23 Painan Utara Kecamatan IV Jurai Kabupaten Pesisir Selatan tahun pelajaran 2018/2019.

\section{KESIMPULAN}

Penelitian ini tidak mengganggu proses pelaksanaan pembelajaran pada bidang yang lain. Dengan adanya penelitian ini, mendorong penulis untuk lebih mempersiapkan diri dalam memberikan pembelajaran pada siswa. Pelaksanaan proses pembelajaran dengan pendekatan Ekplorasi Lingkungan Sekitar pada tema Selamatkan Makhluk Hidup pada siswa kelas VI ini telah dapat meningkatkan aktifitas dan kreatifitas siswa dalam belajar.

\section{DAFTAR RUJUKAN}

Arikunto, S., \& Suhardjono, S. (2006). Penelitian Tindakan Kelas, Jakarta: PT. Buni Aksara.

Cahyani, R., Rustaman, N., Arifin, M., \& Hendriani, Y. (2014). Kemampuan kognisi, kerja ilmiah dan sikap mahasiswa non IPA melalui pembelajaran inkuiri berbantuan multimedia. Jurnal Pendidikan IPA Indonesia, 3(1).

Fadhilaturrahmi, F. (2017). Peningkatan Hasil Belajar Siswa pada Materi Jaring-Jaring Balok dan Kubus dengan Pendekatan Contextual Teaching And Learning (CTL) Siswa Kelas IV SDN 05 Air Tawar Barat. Jurnal Basicedu, 1(1), 1-9.

Holbrook, A. M., Pereira, J. A., Labiris, R., McDonald, H., Douketis, J. D., Crowther, M., et al. (2005). Systematic overview of warfarin and its drug and food interactions. Archives of internal medicine, 165(10), 1095-1106.

Iskandar, R. A., Sukasno, M. P., \& Charli, L. PERBANDINGAN HASIL BELAJAR MATEMATIKA MENGGUNAKAN MODEL PEMBELAJARAN KOOPERATIF TIPE BAMBOO DANCING DAN TIPE NUMBERED HEADS TOGETHER DI KELAS X SMA NEGERI 6 LUBUKLINGGAU TAHUN PELAJARAN 2014/2015 Oleh.

Mahyuddin, R., \& Ariani, Y. (2008). Hand Out Mata Kuliah Metodologi Penelitian Tindakan Kelas. Padang: $U N P$.

Sulistyanto, H., \& Wiyono, E. (2008). ilmu pengetahuan alam. Jakarta: Pusat Perbukuan, Departemen Pendidikan 